\title{
Poison Control Centers Decrease Emergency Healthcare Utilization Costs
}

\author{
Frank LoVecchio, DO ${ }^{a, c}$, Steven C. Curry, MD ${ }^{a, b, c}$, Kathleen Waszolek, $R N^{c}$, \\ Jane Klemens, RNc, Kimberly Hovseth, PAc, Diane Glogan, $R N^{c}$
}

aDepartment of Medical Toxicology, Banner Good Samaritan Medical Center, Phoenix, AZ

bDepartment of Medicine, Banner Good Samaritan Medical Center, Phoenix, AZ

cBanner Poison Control Center, Banner Good Samaritan Medical Center, Phoenix, AZ

\begin{abstract}
Introduction: Patient home management by a regional poison control center has potential to save public healthcare dollars by preventing unnecessary utilization of emergency department services. We wished to conservatively quantify such savings at a large regional poison center and compare savings to funds received in state support.

Methods: Banner Poison Control Center (BPCC) serves a population of about four million in central AZ. A telephone survey of callers who were managed at home in February and March of 2007 after nontoxic exposures was used to calculate what percentage of such callers would have sought unnecessary medical care in emergency departments. Twelve emergency departments geographically dispersed in the region were surveyed, and a state database of hospital charges was queried to determine hospital charges and physician professional charges for conservative management of a patient who would have been advised to remain at home by BPCC.

Results: BPCC managed 28,883 callers at home in 2007. Seventy percent of home-managed patients would have sought unnecessary care in emergency departments. Using most conservative assumptions, a median of \$33 million [range \$18 million to \$45 million] in unnecessary health care charges were prevented by BPCC home-management in 2007. A median of about $\$ 36$ in unnecessary health care charges were prevented for each dollar of state funding BPCC received.

Conclusions: Home management by BPCC provides large dollar savings to residents compared to dollars received in state support.

\section{INTRODUCTION}

Poison control centers (PCCs) certified by the American Association of Poison Control Centers (AAPCC) provide information and advice to prevent and minimize adverse health effects from a poison exposure. This information is provided to the public and healthcare professionals, and centers receive financial support from federal, local, and private sources.

By quickly assessing potentially toxic exposures and making judgments on their severity, poison center personnel frequently manage patients at home with repeat telephone follow-up as needed, preventing unnecessary evaluations in emergency departments, physicians' offices, and urgent care centers. We desired to make conservative estimates on the financial savings to the public through our PCC providing home management.
\end{abstract}

Keywords: Poison control centers, health care utilization, cost savings

Notes: There was no outside funding of any kind used for this study.

Corresponding Author: Frank LoVecchio, DO, Department of Medical Toxicology, Banner Good Samaritan Medical Center, 925 E. McDowell Rd, Phoenix, AZ 85006, Email: Frank.LoVecchio@bannerhealth.com 


\section{METHODS}

Banner Poison Control Center (BPCC) is an AAPCC-certified regional center that serves Maricopa County and central Arizona, a population area of about 4 million. The center's call volume was 105,000 in 2007. Human exposure cases are handled by certified poison information specialists, and medical direction is provided by physicians who are board-certified in medical toxicology and available night and day. Banner PCC is also integrated into the 911 system in that 911 operators frequently patch calls to BPCC and remain on the line to dispatch emergency medical services (EMS) personnel only if poison center personnel make such recommendations. Paramedics and basic life-support personnel also call BPCC from the scene after being directly summoned to determine whether patients require transport to an emergency department (ED) if questions arise concerning the seriousness of exposure.

As part of quality assurance and in efforts to collect data to help better serve callers to BPCC, short surveys are occasionally taken of callers to the center. Between February 1 and April 1, 2007, a brief survey was conducted of persons who called the PCC regarding a human exposure who then underwent home management. Callers were asked to participate in the survey if the exposure represented nonsuicidal ingestion and if the exposure did not require referral to a healthcare facility, but was managed at home with poison center advice and follow-up. The survey was administered by certified poison information specialists only after completion of home management, after obtaining verbal consent, and if specialists had enough time to offer the instrument. The specialist asked, "If the poison center had not been available to provide you assistance, what would you have done?" Answers were placed into 1 of 4 categories (Figure 1). No identifying or demographic information was recorded as part of this survey. Because poison center call volume prevented enough free time for specialists to offer the survey to every consecutive caller, the survey represented a convenience sample, but included callers who called on all shifts on all days of the week. Callers were excluded from the survey if they refused to participate, if they required a healthcare referral, or if the exposure represented an intentional effort at self-harm.

In late 2007, we recognized that information gathered in this survey could be used in calculating a conservative estimate of cost savings when exposed patients were managed at home. From this survey, the percentage of callers who, in the absence of poison center intervention, would have gone directly to an ED or would have summoned EMS (e.g., called 911, an ambulance, or the fire department) was calculated.

The region served by BPCC contained approximately 36 hospital EDs in 2007. Twelve of these EDs geographically spread across Maricopa County and within different zip code zones were surveyed by 1 of the authors. Annual total emergency department visits for these 12 hospitals ranged from 31,000 to 140,000. Hospital coders responsible for coding hospital charges were queried regarding the hospital services that would be billed for an asymptomatic patient who presented to the ED with a history of an accidental or nonsuicidal possible or known exposure to a drug or chemical, who underwent a history and examination, and for whom the ED stay was limited to 1 hour before discharge home. Hospital coders provided the level of emergency services (representing room, nursing services, supplies, etc., but not laboratory or radiology studies) that would be billed (ranging from level 1 through 5 in individual hospitals). The level of emergency services billing provided by each hospital was used to query a database of hospital charges kept by the Arizona Department of Health Services to determine the dollar amount that would be charged by each hospital for the level of service it reported.

Emergency physicians who worked at each of the 12 hospitals and who were responsible for coding physician services (CPT codes) were presented with the same scenario and asked to provide the CPT code that such a visit would typically generate. CPT codes representing physician charges were used to calculate the dollars that would be billed by a physician at each hospital using the charge specifically assigned to that CPT code by that physician group.

Four medical directors of EMS in the Phoenix area were contacted and all stated that virtually every potentially exposed patient who was evaluated after EMS were summoned would be transported to an ED if a PCC was unavailable to provide advice and management, both for patient safety and for medico-legal reasons. Thus, patients who would have summoned EMS would also have received care in an ED.

The group of home-managed patients who would have sought unneeded medical care was defined as the number of patients who would have gone directly to an ED or would have summoned EMS. The number in this group was calculated from survey data and the total number of patients who underwent home management in 2007. This number of patients was multiplied by means and ranges of hospital and physician charges to calculate unneeded healthcare charges that would have been generated without poison center home management.

\section{RESULTS}

During the period of the survey, a total of 7627 human exposure calls were received at BPCC. Surveys were completed on 600 of 610 callers, with only 10 refusing to participate. Of these 600 callers, 219 (37\%) would have summoned EMS, and 199 (33\%) would have gone directly to an ED if the poison center had not been available (Figure 1). These results were almost identical to a similar survey we performed in 1997, in which a total of $69 \%$ of callers would have been placed into these categories.

In 2007, BPCC managed 41,262 human exposures at home. If $70 \%$ of these individuals would have been seen in an $\mathrm{ED}$, then 28,883 unnecessary ED visits were prevented. All hospitals stated that a visit from the patient presented in the scenario would have generated level-4 or level-5 bills, but did not commit to which. Ten of 12 emergency physician billers stated that a visit for the patient described in the scenario would have generated a level-5 


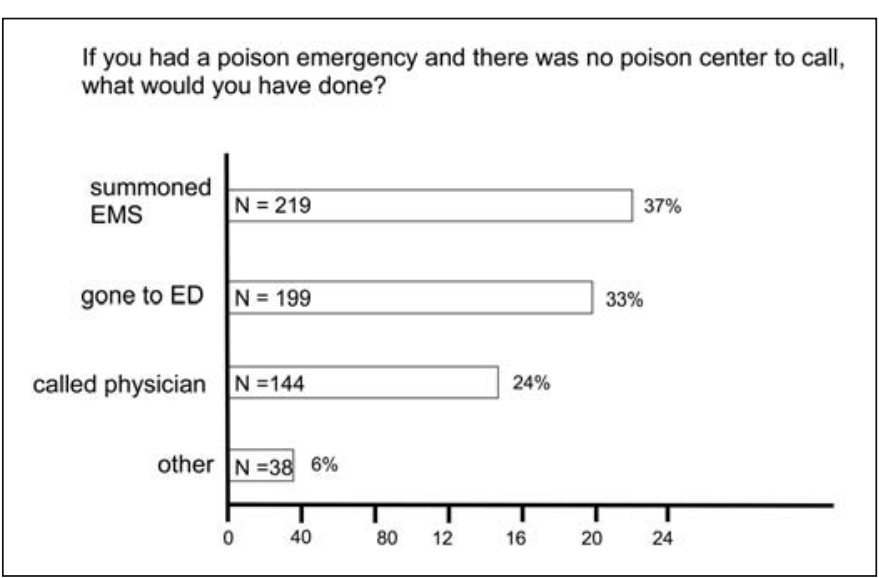

Figure 1: 2007 Survey results. Total number of callers $=600$. $E M S=$ emergency medical services. $E D=$ emergency department.

Table 1: Facility and Physician Fees

\begin{tabular}{llll}
\hline & $\begin{array}{c}\text { Facility fee } \\
\text { dollars } \\
\text { mean (range) }\end{array}$ & $\begin{array}{c}\text { Physician fee } \\
\text { dollars } \\
\text { mean (range) }\end{array}$ & $\begin{array}{c}\text { Total fee } \\
\text { dollars } \\
\text { mean (range) }\end{array}$ \\
\hline Level 2 & $269(107-430)$ & $109(100-115)$ & $378(207-545)$ \\
\hline Level 3 & $440(155-747)$ & $149(130-249)$ & $589(284-996)$ \\
\hline Level 4 & $790(329-1201)$ & $362(301-388)$ & $1152(630-1589)$ \\
\hline Level 5 & $1743(529-1869)$ & $591(477-622)$ & $2334(1006-2491)$ \\
\hline
\end{tabular}

Facility fees represent the dollars charged by hospitals for different levels of basic ED services. Physician fees represent dollars charged by physicians for different levels of physician services, using CPT codes. The level of care a facility chooses to charge may be different from the level of care charged by a physician. bill, and two physicians stated a level-4 bill would have been generated (Table 1).

Table 2 shows calculated unnecessary health-care charges that would have been generated without BPCC home management in 2007. To be conservative, we assumed that all facility charges would be at level 4 , but show results with physician level-4 and physician level-5 billing for illustration. With the most conservative assumptions (both facility and physician level-4 billing), a mean of $\$ 33,270,000$ in unnecessary health-care charges were prevented, with a range from $\$ 18,196,000$ to $\$ 45,895,000$.

In 2007, BPCC received $\$ 925,000$ in funding from the state of Arizona. Thus, a mean of almost \$36 in unnecessary health-care charges were prevented for each dollar of state funding provided.

\section{DISCUSSION}

A few previous studies have demonstrated that regional PCCs significantly decrease the number of patients who seek unnecessary medical care in EDs and physician offices [1-4]. Miller et al. calculated that in 1992, PCCs in the US reduced the number of medically treated nonhospitalized poison cases by 350,000 (25\%) [1]. King and Palmisano reported that after withdrawal of PCC services in Louisiana, self-referral to healthcare facilities following poison exposure increased 4 times, with unnecessary expenses more than 3 times state allocation for PCC services [4]. ChafeeBahamon and Lovejoy studied children under 5 years of age and found that $63 \%$ of those seen in EDs after poison exposure did not require the services of a hospital [2]. Of parents who did not contact the PCC, $44 \%$ went to an ED compared to only $0.5 \%$ of those who called the PCC.

The results of the above studies are in keeping with our findings that $70 \%$ of exposures managed by BPCC at home would have sought care in an ED. This percentage could underrepresent

\begin{tabular}{|c|c|c|c|}
\hline $\begin{array}{l}\text { ED visits } \\
\text { prevented by home } \\
\text { management in } \\
2007\end{array}$ & $\begin{array}{c}\text { Level } 4 \\
\text { facility fee } \\
\text { mean } \\
\text { (median) } \\
\text { [range] }\end{array}$ & $\begin{array}{c}\text { Level } 4 \\
\text { physician fee } \\
\text { mean } \\
\text { (median) } \\
\text { [range] }\end{array}$ & $\begin{array}{c}\text { Total charge } \\
\text { mean } \\
\text { (median) } \\
\text { [range] }\end{array}$ \\
\hline \multirow[t]{2}{*}{28,883} & $\begin{array}{c}22,817,570 \\
(23,412,360) \\
{[9,502,507-34,688,483]}\end{array}$ & $\begin{array}{c}10,455,646 \\
(10,621,021) \\
{[8,693,783-11,206,604]}\end{array}$ & $\begin{array}{c}33,273,216 \\
(34,033,381) \\
{[18,196,290-45,895,087]}\end{array}$ \\
\hline & $\begin{array}{c}\text { Level } 4 \\
\text { facility fee }\end{array}$ & $\begin{array}{c}\text { Level } 5 \\
\text { physician fee }\end{array}$ & Total charge \\
\hline 28,883 & $\begin{array}{c}22,817,570 \\
(25,736,120) \\
{[9,502,507-34,688,483]}\end{array}$ & $\begin{array}{c}17,069,853 \\
(17,211,521) \\
{[13,777,191-17,965,226]}\end{array}$ & $\begin{array}{c}39,887,423 \\
(42,947,641) \\
{[23,279,698-52,653,709]}\end{array}$ \\
\hline \multicolumn{4}{|c|}{$\begin{array}{l}\text { ED = emergency department. The number of prevented visits }(28,883) \text { represents the total number of exposed patients managed } \\
\text { at home in } 2007 \text { multiplied by the fraction }(0.7) \text { of patients who, by survey, would have sought care in an ED (gone to an ED or } \\
\text { summoned emergency medical services). Fees are in dollars. Data are shown with hospital level } 4 \text { and either physician level } 4 \text { or } \\
\text { physician level } 5 \text { values. }\end{array}$} \\
\hline
\end{tabular}


the true percentage since those who reported that they would have called their physician may have been referred by their physician's office to an ED. In a study most similar to ours, Kearney and colleagues conducted a survey of 589 callers in 1991 who were managed at home, reporting that $75 \%$ of callers surveyed would have called an $\mathrm{ED}$, called a physician or other healthcare provider, or would have gone directly to an ED or physician's office [3].

Our study was limited in that our estimate of savings in unnecessary health-care charges to callers was meant to be conservative and, if anything, underestimate true savings. All hospitals stated that a level-5 charge might actually be generated for hospital services. Many physicians may have obtained unneeded basic laboratory studies, urine drug screens, electrocardiograms, or chest radiographs (such as in a child after swallowing a hydrocarbon). Our calculations did not account for these potential charges or those pertaining to cardiac monitoring, intravenous fluids, or administration of medication. Furthermore, callers who summoned EMS would have incurred charges for prehospital treatment and transportation. As noted earlier, some patients who called their physicians' offices would have been referred to EDs, and these charges were not considered in our analysis. Our most conservative estimate also assumed that physicians would bill at level 4 . However, the majority stated they would generate a level-5 bill. Thus savings of unneeded health-care charges were, in reality, significantly greater.

Finally, we did not consider the savings from preventing unnecessary charges to society as a whole. For example, summoning public EMS in Maricopa County frequently results in the dispatch of a paramedic unit comprising a fire engine along with an ambulance, which is an expense to taxpayers. Previous survey data have shown that about $18 \%$ of callers are enrolled in the Arizona Health Care Cost Containment System
(Medicaid), and home management by BPCC directly saved state government from incurring bills for unnecessary services. Home management by BPCC also kept more than 28,000 patients out of already overcrowded emergency departments in Maricopa County, where wait times are some of the longest in the nation.

Home management by BPCC conservatively prevented more than $\$ 33$ million in unnecessary health-care charges in 2007. A minimum of about $\$ 36$ in unnecessary health-care charges were saved for each dollar in state support received by BPCC. Because of conservative assumptions and lack of consideration for savings to government and society in general, savings were actually larger. Our findings are in keeping with the few studies in past years that have found poison control centers to provide very costeffective services to the public.

The authors have no potential financial conflicts of interest to report.

\section{REFERENCES}

1. Miller TR, Lestina DC. Costs of poisonings in the United States and savings from poison control centers: a benefit-cost analysis. Ann Emerg Med 1997;29:239-245.

2. Chafee-Bahamon C, Lovejoy FH: Effectiveness of a regional poison center in reducing excess emergency room visits for children's poisonings. Pediatrics 1983;72:164-169.

3. Kearney TE, Olson KR, Bero LA, Heard SE, Blanc PD: Health care cost effects of public use of a regional poison control center. Western J Med 1996;162:449-504.

4. King WD, Palmisano PA: Poison control centers: Can their value be measured? South Med J 1991;84:722-726. 